\title{
Development of a New Piezoelectric Actuator with Slits
}

\author{
Yasutomo Uetsuji, ${ }^{1}$ Hiroyuki Kuramae, ${ }^{2}$ Kazuyoshi Tsuchiya, ${ }^{3}$ and Hidetoshi Sakamoto ${ }^{4}$ \\ ${ }^{1}$ Department of Mechanical Engineering, Osaka Institute of Technology, 5-16-1 Ohmiya, Asahi-Ku, Osaka 535-8585, Japan \\ ${ }^{2}$ Department of Technology Management, Osaka Institute of Technology, 5-16-1 Ohmiya, Asahi-Ku, Osaka 535-8585, Japan \\ ${ }^{3}$ Department of Precision Engineering, Tokai University, 1117 Kitakaname, Kanagawa, Hiratsuka 259-1292, Japan \\ ${ }^{4}$ Department of Mechanical System Engineering, Kumamoto University, 2-39-1 Kurokami, Chuo-Ku, Kumamoto 860-8555, Japan
}

Correspondence should be addressed to Hiroyuki Kuramae; kuramae@dim.oit.ac.jp

Received 23 May 2013; Accepted 2 July 2013

Academic Editors: S. J. Milne and D. Ricinschi

Copyright (C) 2013 Yasutomo Uetsuji et al. This is an open access article distributed under the Creative Commons Attribution License, which permits unrestricted use, distribution, and reproduction in any medium, provided the original work is properly cited.

\begin{abstract}
A piezoelectric actuator was developed for fluid pumps in health monitoring systems. We devised a piezoelectric actuator with some slits, which allows the stretching and contracting deformation in in-plane direction and creates large deflection in out-ofplane direction. The static behaviors under uniform electric field have been analyzed by finite element method. And then, the optimum geometry of slits was searched by response surface methodology for unimorph and bimorph actuators to output the largest deflection under various fixed conditions. The computational results indicated that a bimorph actuator with cross-shaped slit under outside-fixed condition has superior performance for fluid pumps. The proposed slit-inserted actuators have been manufactured as an experiment. As a result, it was verified that the developed actuator can amplify the deflection compared with conventional nonslit actuators.
\end{abstract}

\section{Introduction}

New medical devices, which can extract blood and detect some health indicators such as blood sugar count, are desired for an aging society in Japan. The actuator for blood extraction pump is one of the important elements for these health monitoring systems. In case of a prototype of the above-mentioned health monitoring system called "(Biomimetic-Medical Electronics Machine) Bio-MEM" [1], a piezoelectric element was employed for the pump actuator because of its fast response and precession control. In case of other various electromechanical devices, piezoelectric elements with various configurations were also utilized for pumping [2-7]. Every pump vacuums and discharges the fluids with volumetric change produced by the actuation of the piezoelectric element. Consequently, it is important for performance upgrade of fluid pumps to amplify the deflection of piezoelectric actuators.

There are two approaches for improving performance of piezoelectric-actuated fluid pumps. One is to develop novel materials with higher piezoelectricity. It is well known that various materials such as quarts $\left(\mathrm{SiO}_{2}\right)$ and zinc oxide
$(\mathrm{ZnO})$ provide piezoelectricity. Especially perovskite oxides expressed with a chemical formula $\mathrm{ABO}_{3}$ provide excellent piezoelectric performance, and they are represented by barium titanate $\left(\mathrm{BaTiO}_{3}\right)$, lead titanate $\left(\mathrm{PbTiO}_{3}\right)$, and lead zirconium titanate ( $\mathrm{PZT}: \mathrm{Pb}(\mathrm{Zr}, \mathrm{Ti}) \mathrm{O}_{3}$ ) ceramics. The important feature of these ceramics is ferroelectricity. Namely, they have a spontaneous polarization caused by noncentrosymmetric crystal structure and can change its direction by external loads, which is commonly referred to as domain switching. In poling process, the domain switching can arrange microscopic random polarization, and it leads these ceramics into a macroscopic large piezoelectricity. PZT ceramics have particularly excellent piezoelectric properties. On the other hand, because PZT ceramics include the hazardous lead, a lot of lead-free piezoelectric materials are researched energetically [8-10]. In general, most of lead-free piezoelectric materials are inferior to PZT ceramics. Although some excellent novel lead-free piezoelectric materials were fabricated, they are not widely in practical use. It will require more time to apply novel lead-free piezoelectric materials to fluid pumps. Consequently, it is difficult to improve the pump performance immediately by employing novel piezoelectric materials. 


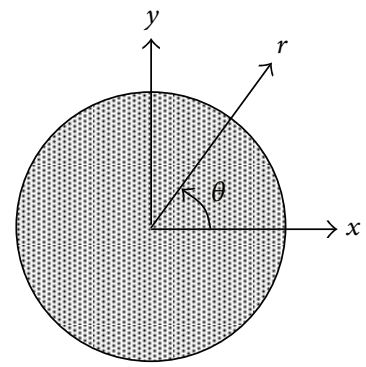

(a) Nonslit

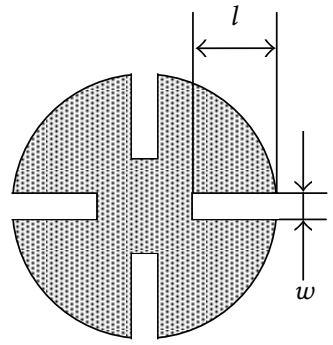

(b) Outside slit

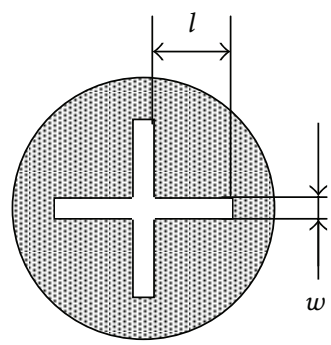

(c) Cross slit

FIGURE 1: Geometries of piezoelectric elements.

The other approach for improving performance is structural design of piezoelectric actuators. Piezoelectric actuators can be classified into three types. One is monomorph actuator, that is a piezoelectric ceramic plate. If an electric filed is applied in the thickness direction, the monomorph actuator extends along the out-of-plane direction and shrivels along the in-plane direction. If employing the note of piezoelectric strain constant $d_{\text {mij }}$, mechanical strains, outof-plane strain $\varepsilon_{33}$, and in-plane strain $\varepsilon_{11}\left(=\varepsilon_{22}\right)$ can be expressed as $d_{333} E_{3}$ and $d_{311} E_{3}$, respectively. $E_{3}$ notes the electric filed applied in the thickness direction. Next, is unimorph actuator consisting of a piezoelectric ceramic plate and a metal thin plate. The unimorph actuator is deflected by the difference of the in-plane strain between the piezoelectric ceramic plate and the metal thin plate. The other is bimorph actuator composed of two piezoelectric ceramic plates bonded together. The bimorph actuator reverses the deformation of two piezoelectric plates by opposite electric filed, and it leads to the generation of a large deflection. In general, unimorph or bimorph piezoelectric actuator is utilized for fluid pumps. Both piezoelectric actuators can generate a large deflection when they are free to deform in the in-plane direction. It is however difficult to generate a large deflection in usage environment because the inplane deformation is often intercepted when the piezoelectric actuators are attached to devices.

In this study, a new piezoelectric actuator with some slits is proposed for fluid pumps. The slit of piezoelectric element has two workings. One is to reduce the overall bending rigidity of actuator, and the other is to allow the in-plane deformation under fixed conditions [11]. This paper targets a disk-shaped piezoelectric actuator and focuses on two types of slit, which are the outside slit and cross slit. The amplification of deflection is verified through finite element simulations. The deflection is compared between unimorph and bimorph piezoelectric actuators. The influence of general fixed conditions on the deflection is investigated. Additionally, two geometric parameters, such as slit length and width, are set to design parameter, and the optimum geometry of slit is searched by the response surface methodology to output the largest deflection. Finally, a prototype of the proposed piezoelectric actuator with slit is manufactured, and the superiority and availability are verified experimentally.
TABLE 1: Material properties of PZT ceramics.

\begin{tabular}{lccccc}
\hline $\begin{array}{l}\text { Elastic stiffness } \\
\text { constant }(\mathrm{GPa})\end{array}$ & \multicolumn{2}{l}{$\begin{array}{l}\text { Piezoelectric stress } \\
\text { constant }\left(\mathrm{pC} / \mathrm{m}^{2}\right)\end{array}$} & $\begin{array}{l}\text { Relative dielectric } \\
\text { constant }\end{array}$ \\
\hline$C_{11}^{E}, C_{22}^{E}$ & $1.3 \times 10^{2}$ & $e_{13}, e_{23}$ & -16.2 & $\epsilon_{11}^{S}, \epsilon_{22}^{S}$ & 4400 \\
$C_{12}^{E}$ & 86.6 & $e_{33}$ & 21.6 & $\epsilon_{33}^{S}$ & 5500 \\
$C_{13}^{E}, C_{23}^{E}$ & 86.0 & $e_{24}, e_{15}$ & 19.7 & & \\
$C_{33}^{E}$ & $1.2 \times 10^{2}$ & & & & \\
$C_{44}^{E}, C_{55}^{E}$ & 24.0 & & & & \\
$C_{66}^{E}$ & 29.5 & & & & \\
\hline
\end{tabular}

\section{New Actuator with Slit}

2.1. Geometry and Fixed Condition. Unimorph and bimorph actuators, which are generally used for fluid pumps, deform in not only out-of-plane direction, but also in-plane direction. Since the in-plane deformation of these actuators is intercepted by fixation to devices, the out-of-plane deformation decreases if compared with one under unconstrained conditions. Consequently, the insertion of slit is effective to make the in-plane deformation free even if the actuator is fixed to devises. Figure 1 demonstrates three types of piezoelectric element. First is Figure 1(a), a conventional piezoelectric element without slit. Next is Figure 1(b), a new piezoelectric element with outside slit along radial direction. Final is also Figure 1(c), a new piezoelectric element with cross slit. Even if the periphery of actuator is fixed, the slit allows enough inplane deformation of piezoelectric element and the actuator keeps large out-of-plane deformation.

Figure 2 shows the stacking configuration of Figure 2(a) unimorph and Figure 2(b) bimorph actuators. Both actuators are a disk with $10 \mathrm{~mm}$ diameter. The unimorph actuator is composed of a piezoelectric element with $0.9 \mathrm{~mm}$ thickness and a metal plate with $0.1 \mathrm{~mm}$ thickness. The bimorph actuator consists of two piezoelectric elements with $0.9 \mathrm{~mm}$ thickness and a metal plate with $0.1 \mathrm{~mm}$ thickness. The metal plate plugs a leak of fluid. In this work, copper was employed for the metal plate, and PZT (C-91H, Fuji ceramics co.) was used for the piezoelectric element. Material properties of PZT are listed in Table 1. 


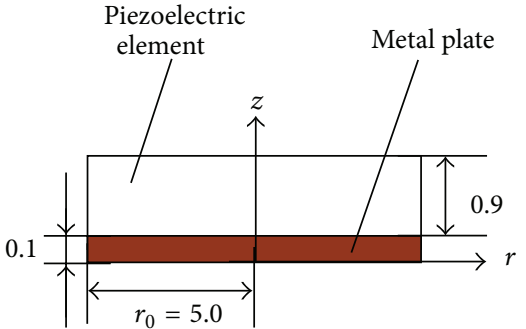

(a) Unimorph

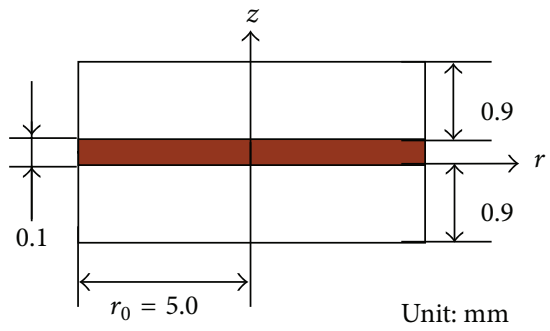

(b) Bimorph

FIGURE 2: Stacking configuration of piezoelectric actuators.

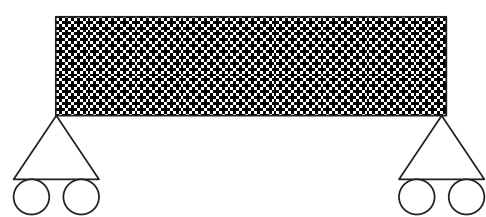

(a) Nonfixed

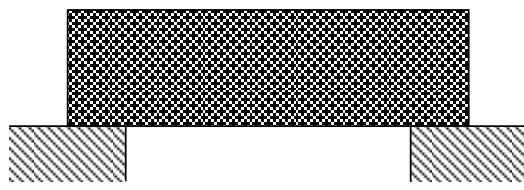

(c) One-side fixed

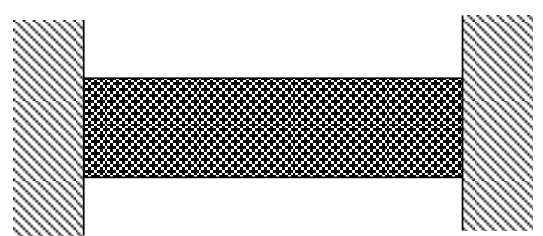

(b) Outside fixed

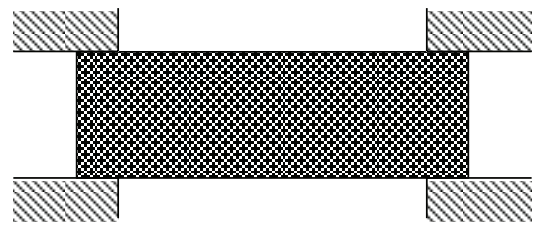

(d) Two-side fixed

Figure 3: Fixed conditions of piezoelectric actuators.

Figure 3 shows boundary conditions for piezoelectric actuators. In this work, four types of boundary condition were set to analyze the influence of fixation. First was a nonfixed condition which was free for in-plane deformation. Second was an outside fixed condition. The outer circumferential surface was perfectly fixed in all directions. Third and final were a one-side and a two-side fixed conditions, respectively. The outer circumferential ring with $1.0 \mathrm{~mm}$ width on lower and/or upper surface was perfectly fixed in all directions.

2.2. Advantageous Effect of Slit on Deflection. In order to understand the advantageous effect of slit, the deflection curve was compared among three type actuators in Figure 1. The length $(l)$ and the width $(w)$ of the outside slit were set to $3.25 \mathrm{~mm}$. The length and the width of, cross slit were set to $3.00 \mathrm{~mm}$. In case of Figure 1(a), the unimorph actuator, electric potential of the metal plate was $0.0 \mathrm{~V}$, and one of the upper surface of piezoelectric element was $1.0 \mathrm{~V}$. In case of Figure 1(b), the bimorph actuator, electric potential of the metal plate was also $0.0 \mathrm{~V}$, and one of upper and lower surfaces of piezoelectric element was $1.0 \mathrm{~V}$. A unit electric voltage, $1.0 \mathrm{~V}$, was applied to every piezoelectric element.

In case that the boundary condition was set to the nonfixed state (Figure 3(a)), Figure 4 presents the comparison of deflection curves among three type actuators. The horizontal axis indicates radial location from the center of disk-shaped actuator. In the same way, Figure 5 shows the computational results in case of the outside-fixed state (Figure 3(b)). At first, we focus on the conventional actuator without slit. In case of the nonfixed state, the nonslit unimorph actuator is deflected upward since piezoelectric element becomes extended in the in-plane direction. The nonslit bimorph actuator is also deflected upward since the upper piezoelectric element becomes extended and the lower shrivels in the in-plane direction. In contract, the nonslit unimorph and the nonslit bimorph actuators generate very little deflection under outside-fixed condition as shown in Figure 5 because the in-plane deformation is not allowed. Next, we move to new slit-inserted actuators. In case of the nonfixed state, the slit-inserted unimorph and the slit-inserted bimorph actuators are deflected upward, similar to the conventional actuator. Additionally, the slit-inserted unimorph and the slit-inserted bimorph actuators generate large deflection on the downward side even if they are under the outside-fixed state.

\section{Geometric Optimization}

3.1. Bimorph Actuator with outside Slit. The bimorph actuator with outside slit was selected as a typical example, and the influence of slit geometry on the deflection was investigated through finite element simulation. Figure 6(a) presents the influence of slit length on the deflection curve in case that the slit width was set to a constant value, $3.25 \mathrm{~mm}$. Additionally, 


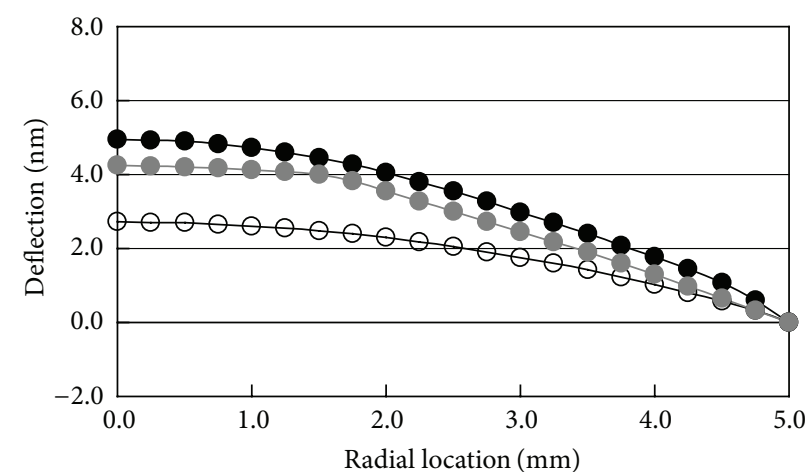

$\ominus$ Nonslit

-C Outside slit $(l=3.25 \mathrm{~mm}, w=3.25 \mathrm{~mm})$

$\multimap$ Cross slit $(l=3.00 \mathrm{~mm}, w=3.00 \mathrm{~mm})$

(a) Unimorph

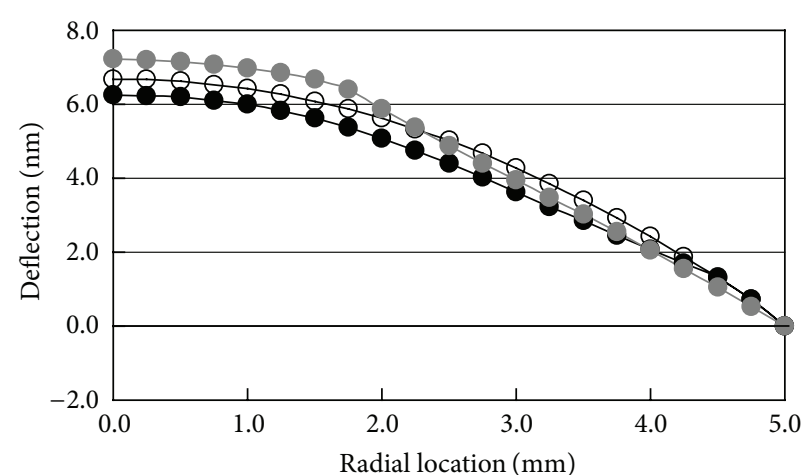

- Nonslit

-C Outside slit $(l=3.25 \mathrm{~mm}, w=3.25 \mathrm{~mm})$

- Cross slit $(l=3.00 \mathrm{~mm}, w=3.00 \mathrm{~mm})$

(b) Bimorph

Figure 4: Comparison of deflection curves among piezoelectric actuators with and without slits under a non-fiexed condition.

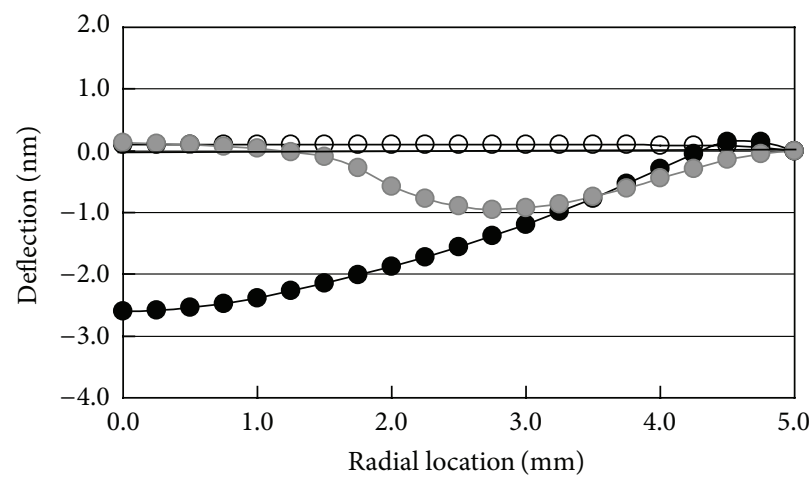

$\multimap$ Nonslit

- Outside slit $(l=3.25 \mathrm{~mm}, w=3.25 \mathrm{~mm})$

$\multimap$ Cross slit $(l=3.00 \mathrm{~mm}, w=3.00 \mathrm{~mm})$

(a) Unimorph

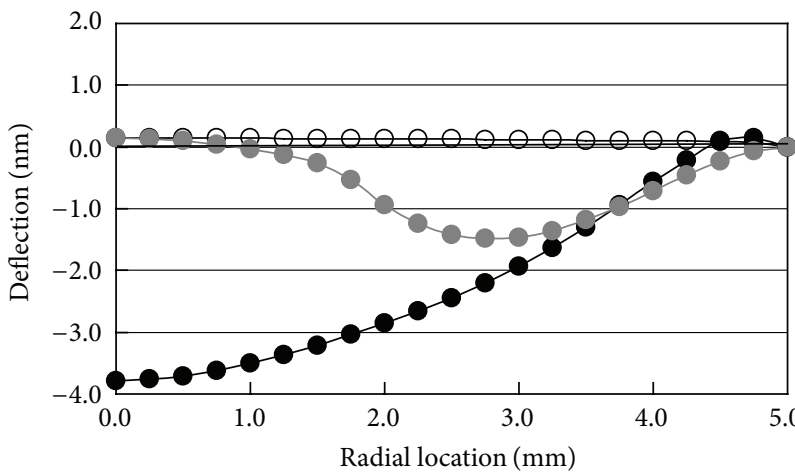

- Nonslit

-O Outside slit $(l=3.25 \mathrm{~mm}, w=3.25 \mathrm{~mm})$

$\multimap$ Cross slit $(l=3.00 \mathrm{~mm}, w=3.00 \mathrm{~mm})$

(b) Bimorph

FIGURE 5: Comparison of deflection curves among piezoelectric actuators with and without slits under outside-fixed condition.

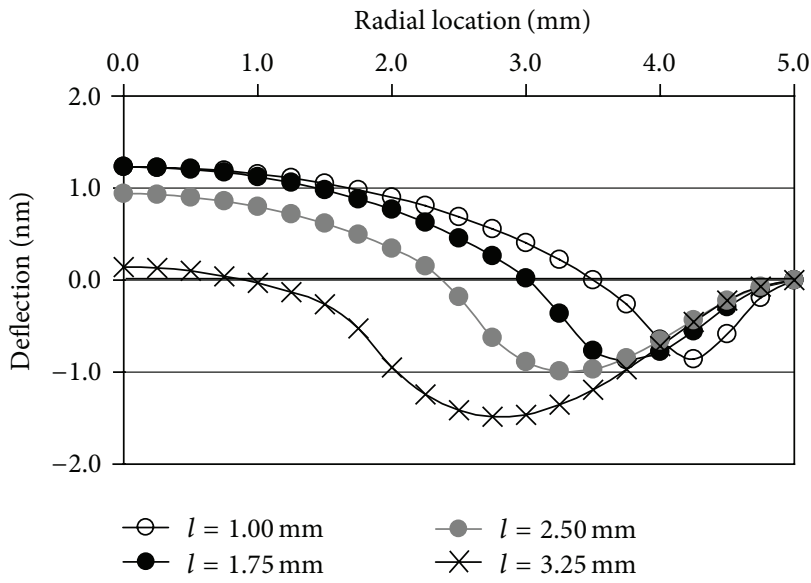

(a) $w=3.25 \mathrm{~mm}$

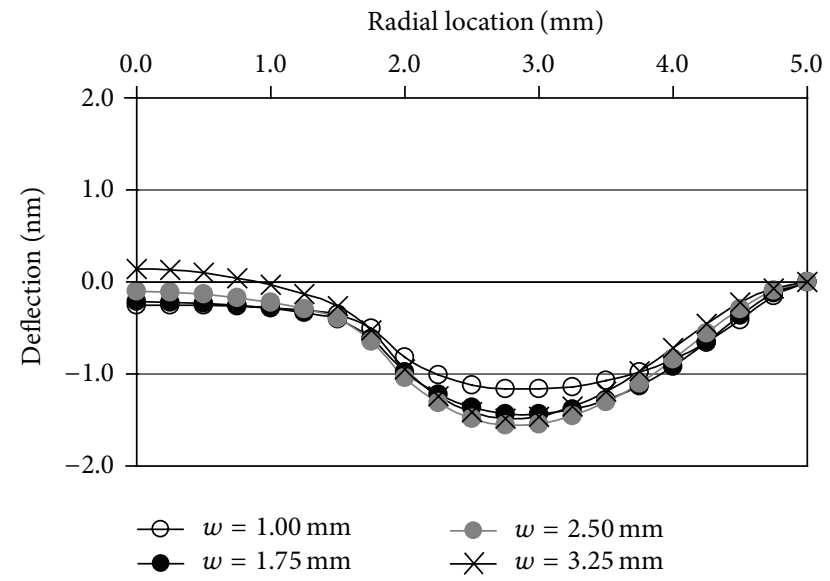

(b) $l=3.25 \mathrm{~mm}$

FIGURE 6: Influence of slit geometry on deflection curve in case of bimorph actuator with outside slit. 


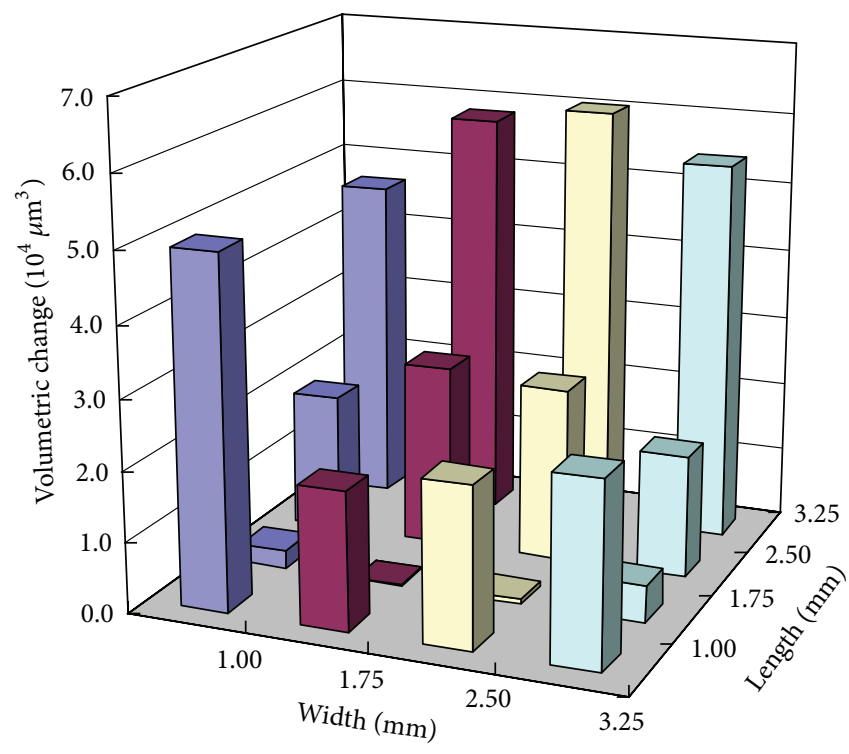

(a) Finite element solutions

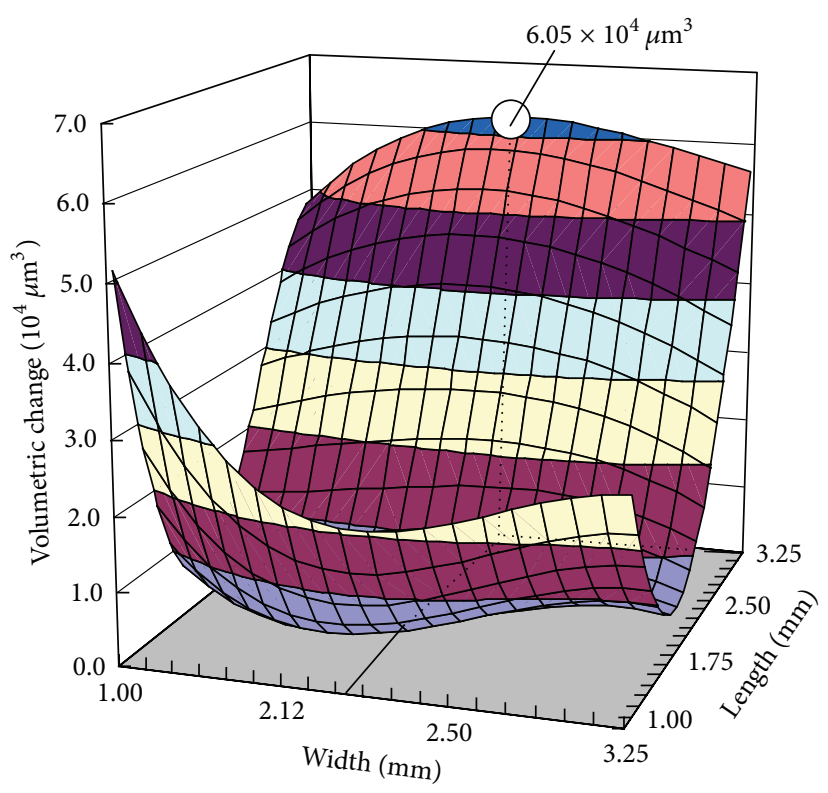

(b) Response surface methodology

FIGURE 7: Influence of slit geometry on volumetric change in case of bimorph actuator with outside slit.

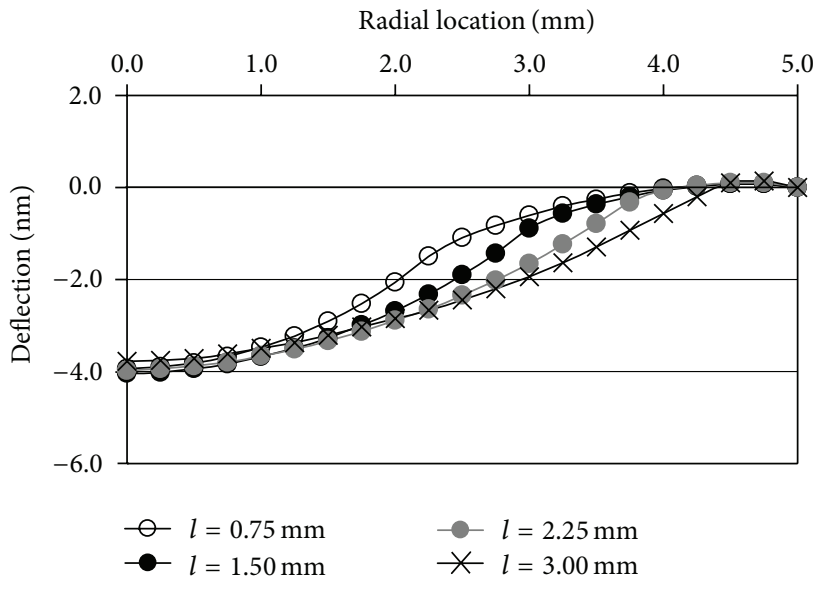

(a) $w=3.00 \mathrm{~mm}$

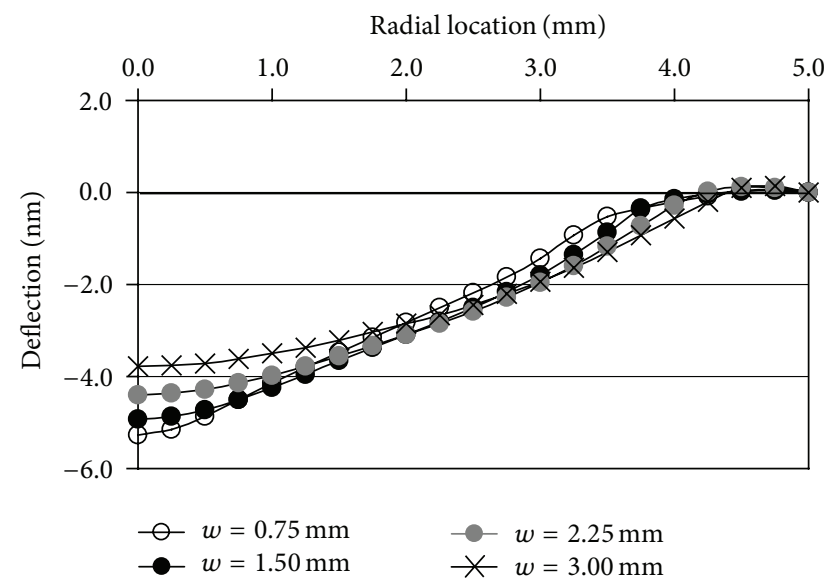

(b) $l=3.00 \mathrm{~mm}$

FIGURE 8: Influence of slit geometry on deflection curve in case of bimorph actuator with cross slit.

Figure 6(b) shows the influence of slit width on the deflection curve in case of keeping the slit length $3.25 \mathrm{~mm}$. Whereas the central part of piezoelectric actuator with outside slit is deflected on the upward side, the outer circumferential part, in which the outside slit was set, is deflected on the opposite side. As the slit length increases, the upper deflection of central part becomes smaller and the lower deflection of outer circumferential part becomes larger. On the other hand, the deflection does not vary significantly according to the increase of the slit width.

Figure 7(a) shows finite element solutions for volumetric change when the length and the width of slit were changed from $1.00 \mathrm{~mm}$ to $3.25 \mathrm{~mm}$. The first and the second horizontal axes are the length and the width of slit, respectively. The vertical axis indicates the volumetric change caused by actuation of the piezoelectric actuator under a unit electric voltage. In order to search the optimum geometry for maximum volumetric change, Figure 7(b) presents the computational result smoothed by the response surface methodology. Figure 7 indicates that the volumetric change is more sensitive to the length than the width of slit. Additionally, it clears up that the volumetric change becomes the maximum, $6.05 \times 10^{4} \mu \mathrm{m}^{3}$ at $3.25 \mathrm{~mm}$ length and $2.12 \mathrm{~mm}$ width.

3.2. Bimorph Actuator with Cross Slit. In the same way with outside slit, Figure 8(a) shows the comparison of the deflection curve of cross slit-inserted bimorph actuator in case of changing the slit length under a constant width. 


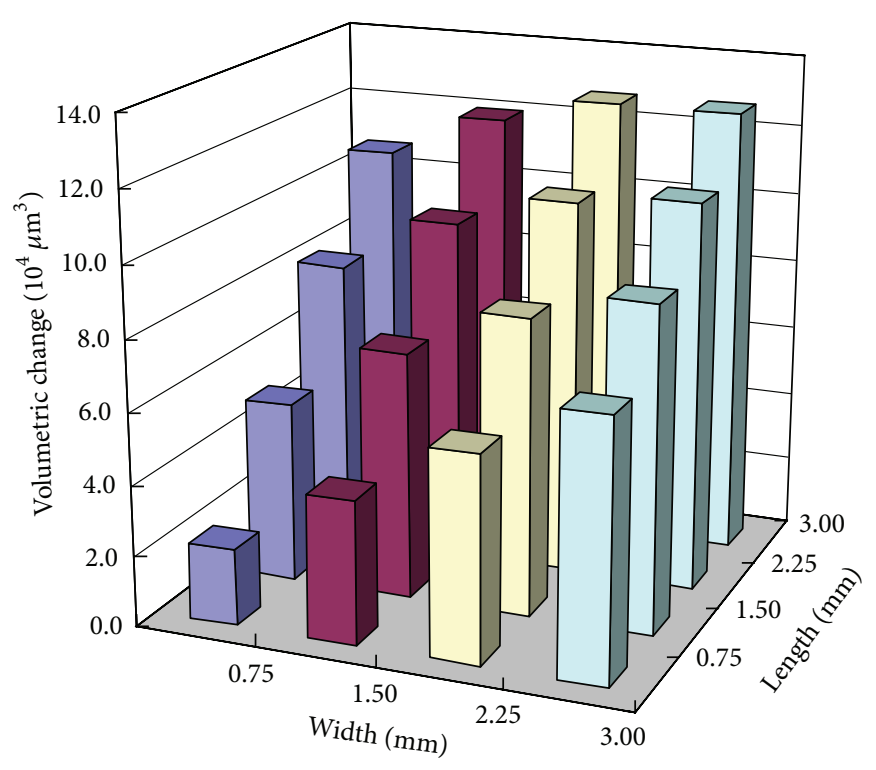

(a) Finite element solutions

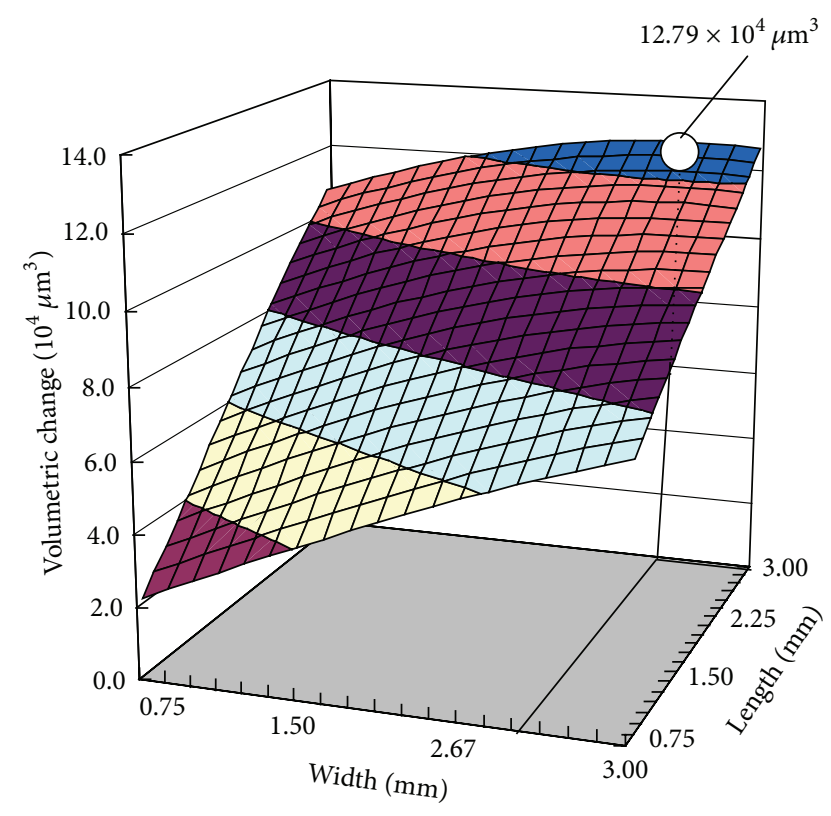

(b) Response surface methodology

FIGURE 9: Influence of slit geometry on volumetric change in case of bimorph actuator with cross slit.

Figure $8(\mathrm{~b})$ is the computational result in case of changing the slit width under a constant length. The bimorph actuator is deflected on the downward side in case of any slit geometry. The influence of slit geometry is smaller than the outside slit. Figure 9(a) shows finite element solutions for volumetric change when the length and the width of slit were changed from $0.75 \mathrm{~mm}$ to $3.00 \mathrm{~mm}$. Furthermore, Figure 9(b) presents the computational result smoothed by the response surface methodology. There is an obvious tendency that the volumetric change increases as the length and the width become larger. The response surface methodology indicates that the volumetric change becomes the maximum, $12.79 \times 10^{4} \mu \mathrm{m}^{3}$ at $3.00 \mathrm{~mm}$ length and $2.67 \mathrm{~mm}$ width.

3.3. Optimum Slit Geometry and Fixed Condition. The optimization of slit geometry was carried out through the response surface methodology for all conditions, which includes two types of stacking configuration (unimorph and bimorph), three types of slit (nonslit, outside slit, and cross slit), and three types of fixed condition (outside, oneside and two-side fixed conditions). Figure 10 compares the maximum volumetric change among three-fixed conditions. In case of Figure 10(a) conventional nonslit actuators, the one-side fixed condition presents the maximum volumetric change. In particular, the bimorph actuator is superior to the unimorph actuator. In case of Figure 10(b) outside slit, the unimorph and the bimorph actuators have the maximum under different fixed condition. The optimum geometry of slit is also variant between two actuators. The former is the one-side fixed condition and large width; small length slit is better. In contrast, the latter is the outside-fixed condition and comparatively-small width; large length slit is superior. In case of Figure 10(c) cross slit, the bimorph actuator under the outside-fixed condition presents the maximum volumetric change.

If all computational results are summarized, Figure 11 shows the comparison of the maximum volumetric change among three types of fixed condition. The bimorph actuator under the outside-fixed condition presents the largest volumetric change of all conditions, which attains to more than twice of the conventional actuator.

\section{Experiment Verification}

4.1. Prototype of New Piezoelectric Actuators. In order to verify the superiority of the slit-inserted actuators, prototypes of the bimorph actuators with outside and cross slits were manufactured. A prototype of the nonslit bimorph actuator was also manufactured as a reference. Figure 12 shows the manufactured prototypes of bimorph actuator, which are Figure 12(a) nonslit, Figure 12(b) outside slit-inserted, and Figure 12(c) cross slit-inserted actuators. PZT (C-91H, Fuji ceramics co.) was used for the piezoelectric element. The diameter and the thickness of piezoelectric element were $20.0 \mathrm{~mm}$ and $0.5 \mathrm{~mm}$, respectively. The slits were fabricated by laser. The width and the length of outside slit were set to $0.50 \mathrm{~mm}$ and $2.0 \mathrm{~mm}$ because of the process limitation. On the other hand, the width and the length of cross slit were set to $0.50 \mathrm{~mm}$ and $4.0 \mathrm{~mm}$.

4.2. Deflection Measurement. As shown in Figure 12, the prototypes of bimorph actuator were bonded with plastic jig to be under the outside-fixed condition. The alternating voltage, $3.0 \mathrm{~V}$ was applied to every piezoelectric element. The frequency of voltage was changed from $1000 \mathrm{~Hz}$ to $7400 \mathrm{~Hz}$. The center of bimorph actuator was measured by 


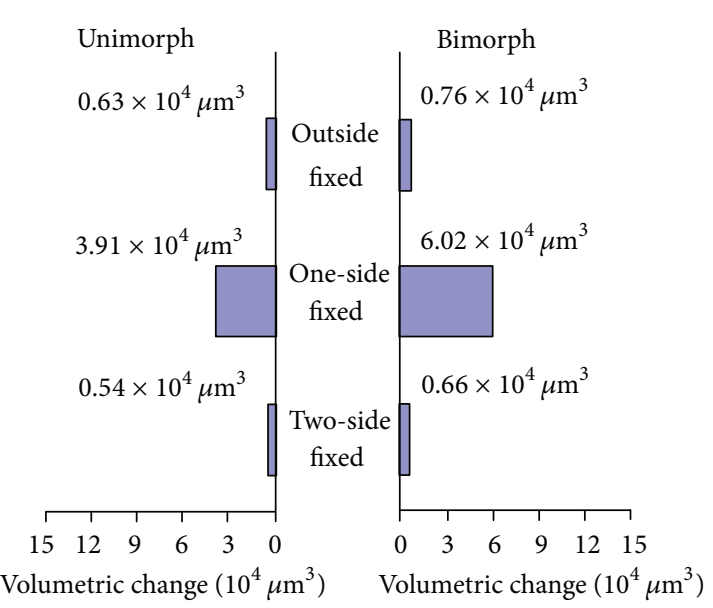

(a) Non slit

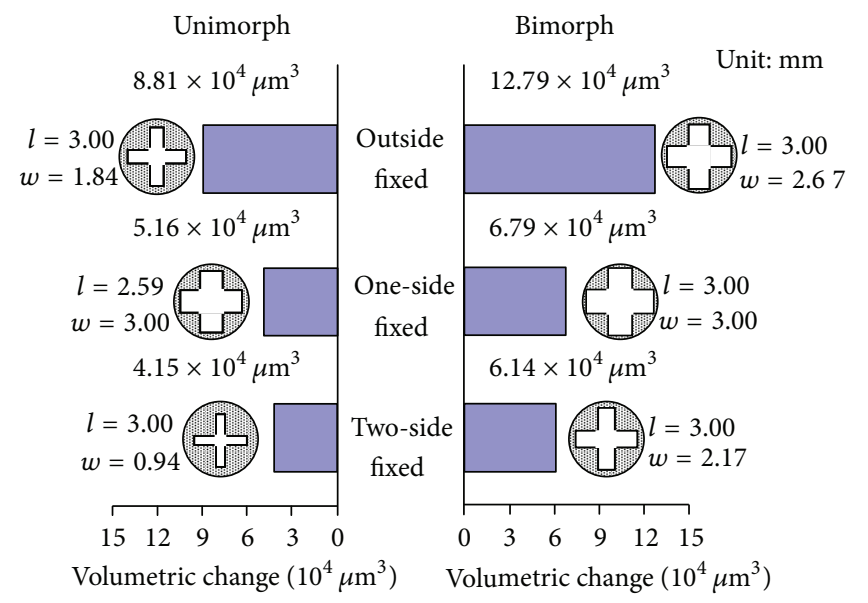

(c) Cross slit

Volumetric change $\left(10^{4} \mu \mathrm{m}^{3}\right) \quad$ Volumetric change $\left(10^{4} \mu \mathrm{m}^{3}\right)$

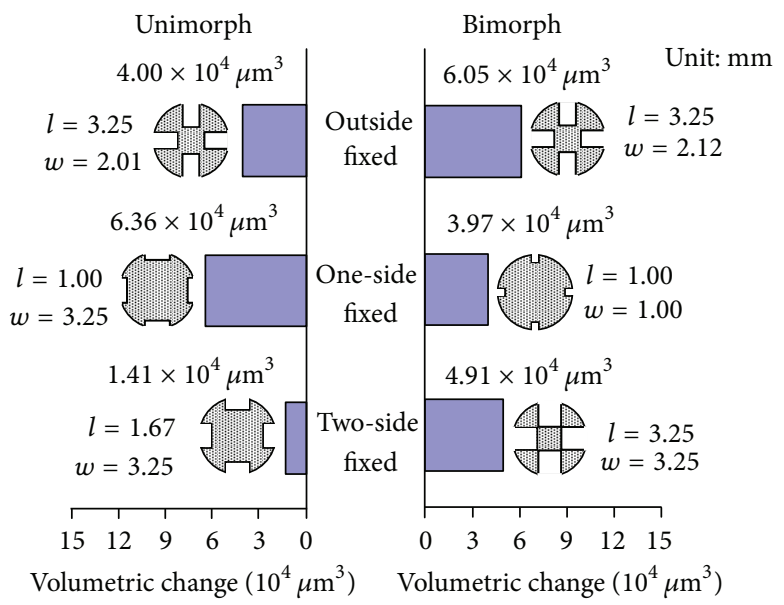

(b) Outside slit

FIGURE 10: Comparison of volumetric change of the optimized unimorph and bimorph actuators among three types of fixed condition.

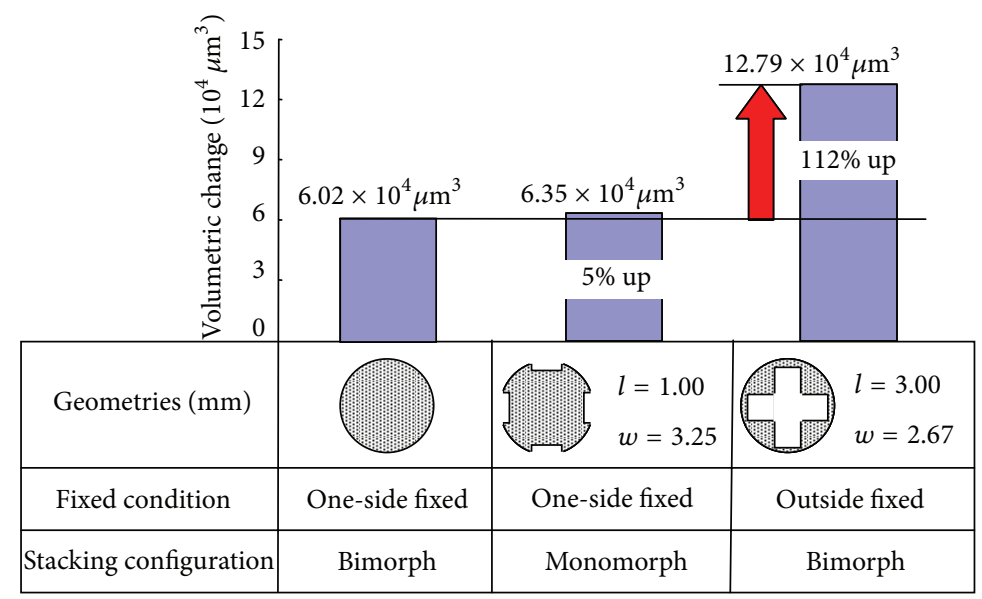

FIGURE 11: Comparison of maximum volumetric change among nonslit, outside slit-inserted, and cross slit-inserted actuators under each optimum condition. 


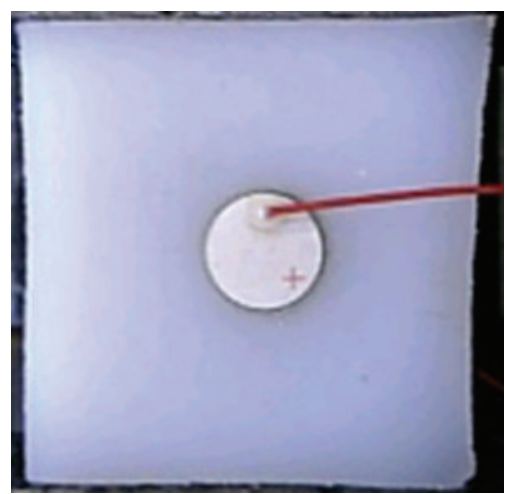

(a) Non slit

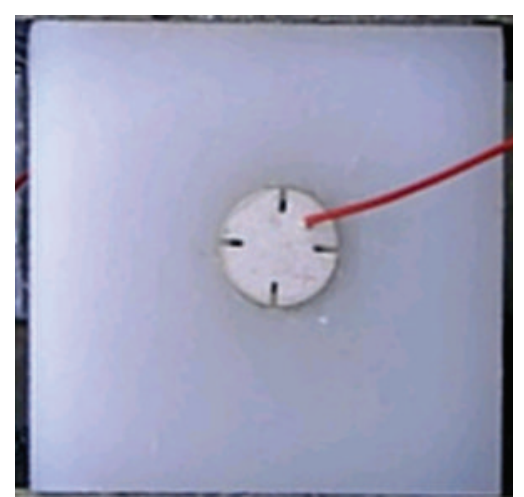

(b) Outside slit

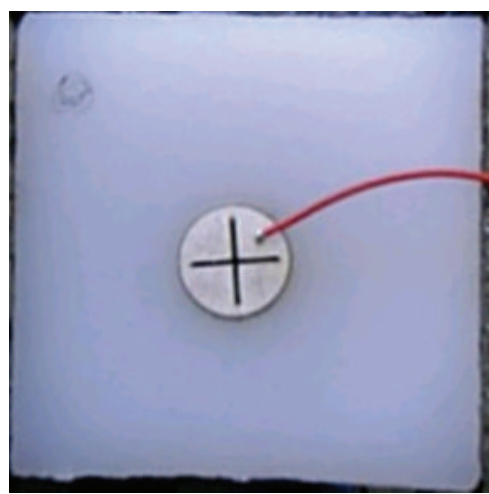

(c) Cross slit

FIGURE 12: Manufactured bimorph actuators fixed in testing jig.

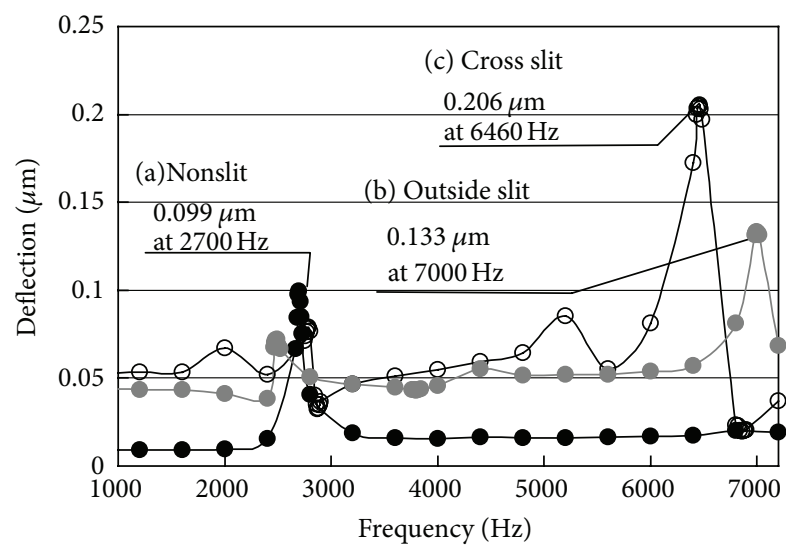

FIGURE 13: Experimental result of amplitude-frequency response for bimorph actuators.

a laser Doppler vibrometer (AT-3700, Graphtec co.). Figure 13 shows the experimental results for deflection measurement. First, resonance points are compared among three bimorph actuators. In case of nonslit actuator, resonance point appears at $2700 \mathrm{~Hz}$, and the deflection reaches $0.099 \mu \mathrm{m}$. The resonant frequency and its deflection of the outside slit actuator are $7000 \mathrm{~Hz}$ and $0.133 \mu \mathrm{m}$. Those of the cross slit actuator are $6460 \mathrm{~Hz}$ and $0.206 \mu \mathrm{m}$. In addition, the superiority of slitinserted actuators can be confirmed at low frequency range except resonance point.

\section{Conclusions}

A new piezoelectric slit-inserted actuator was proposed for fluid pumps. The superiority of the proposed actuators was verified by finite element simulation. As a result of geometric optimization by the response surface methodology, the proposed bimorph actuators with outside and cross slits showed $5 \%$ and $112 \%$ increase, respectively, compared with the conventional nonslit actuator. Additionally, the deflection measurement proved that the outside and the cross slits provide 1.34 and 2.08 times upgrade. This performance upgrade by structural design will contribute to accelerating the application of novel lead-free piezoelectric materials.

\section{Acknowledgments}

The authors would like to express their thanks to Dr. Hishim Hwang and Mr. Kei Fukuda of Osaka Institute of Technology for assistance during this research. One of the authors (Y. Uetsuji) was financially supported by a Grant-in-Aid for Young Scientists (B) (no. 22760087) from the Ministry of Education, Culture, Sports, Science and Technology of Japan.

\section{References}

[1] K. Tsuchiya, N. Nakanishi, T. Kometa, Y. Uetsuji, K. Mori, and E. Nakamachi, "Development of blood extraction system for bioMEM," Transactions of the Japan Society of Mechanical Engineers C, vol. 71, no. 702, pp. 603-609, 2005.

[2] Y. Kojima, T. Okusawa, K. Tsubouchi, Y. Takagi, and N. Hamano, "Fundamental investigation of piezo-driven pump feeding a trace of liquid," Transactions of the Japan Society of Mechanical Engineers C, vol. 58, no. 556, pp. 3511-3516, 1992.

[3] H. Nagata et al., "Development of a piezoelectric bimorph element for piezoelectric pumps," Journal of Tosoh Research, vol. 37, no. 2, pp. 95-100, 1993.

[4] M. Kidera, H. Tsukamoto, and K. Miyazaki, "A valveless micropump driven by a piezoelectric device," Turbomachinery, vol. 31, no. 7, pp. 435-439, 2003.

[5] T. Zhang and Q.-M. Wang, "Performance evaluation of a valveless micropump driven by a ring-type piezoelectric actuator," IEEE Transactions on Ultrasonics, Ferroelectrics, and Frequency Control, vol. 53, no. 2, pp. 463-473, 2006.

[6] Y. Konishi, "Infusion pump," Japanese Society of Medical Instrumentation, vol. 73, no. 8, pp. 395-400, 2003.

[7] Y. Konishi, "Fluid pump by piezoelectric element," Journal of the Japan Fluid Power System Society, vol. 30, no. 7, pp. 28-32, 1999.

[8] M. G. Stachiotti, C. O. Rodriguez, C. Ambrosch-Draxl, and N. E. Christensen, "Electronic structure and ferroelectricity in $\mathrm{SrBi}_{2} \mathrm{Ta}_{2} \mathrm{O}_{9}$," Physical Review B, vol. 61, no. 21, pp. 14434-14439, 2000. 
[9] H. Kumagai, "Piezoelectric properties and potential applications of potassium niobate single crystals," Ceramics Japan, vol. 35, pp. 360-362, 2000.

[10] Y. Saito, H. Takao, T. Tani et al., "Lead-free piezoceramics," Nature, vol. 432, pp. 84-87, 2004.

[11] Y. Uetsuji, H. Nagakura, S. Kawahara et al., "Proposal of a new bimorph piezoelectric actuator for blood extraction pump in health monitoring system," Journal of the Society of Materials Science, vol. 56, no. 5, pp. 477-482, 2007. 

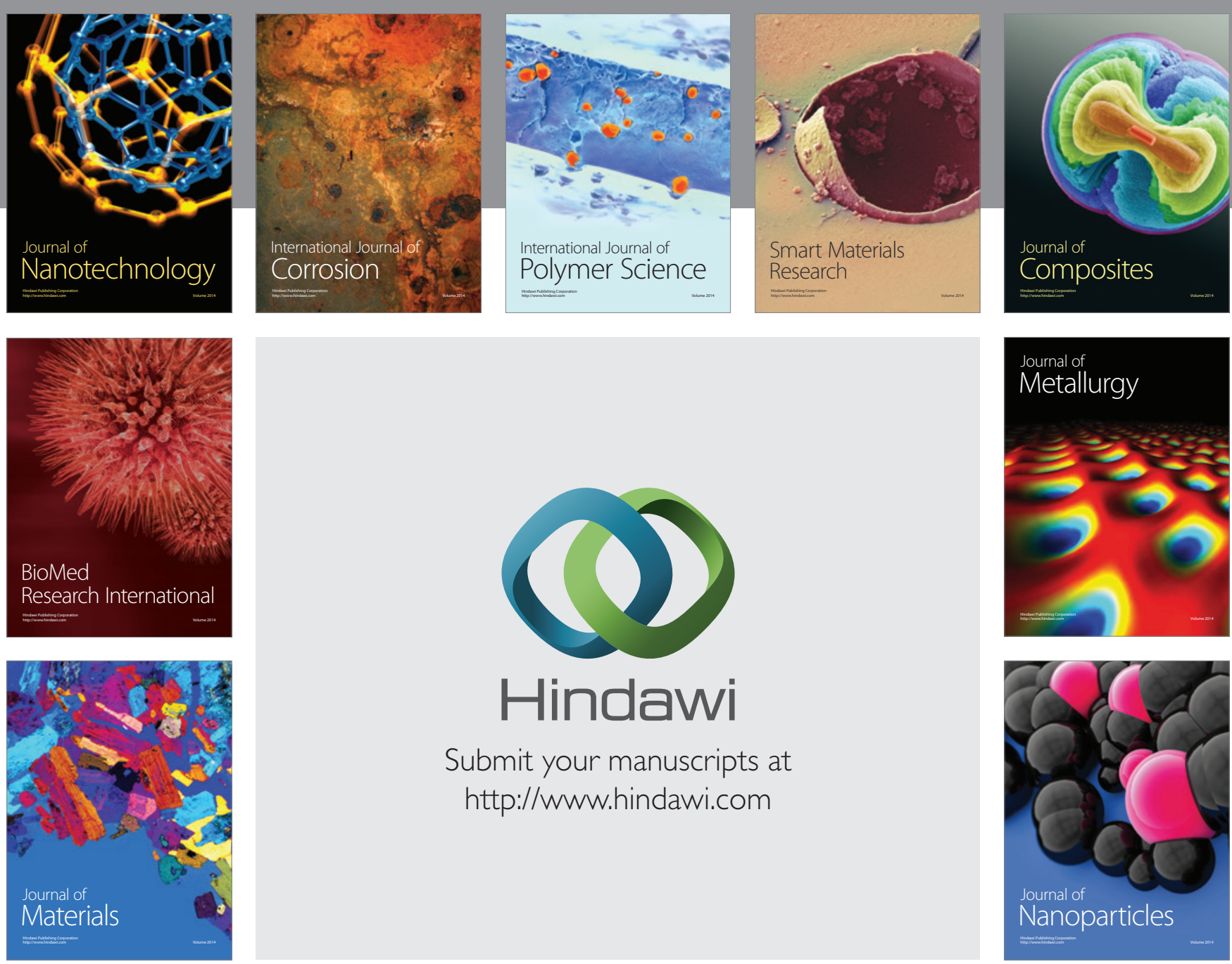

Submit your manuscripts at http://www.hindawi.com
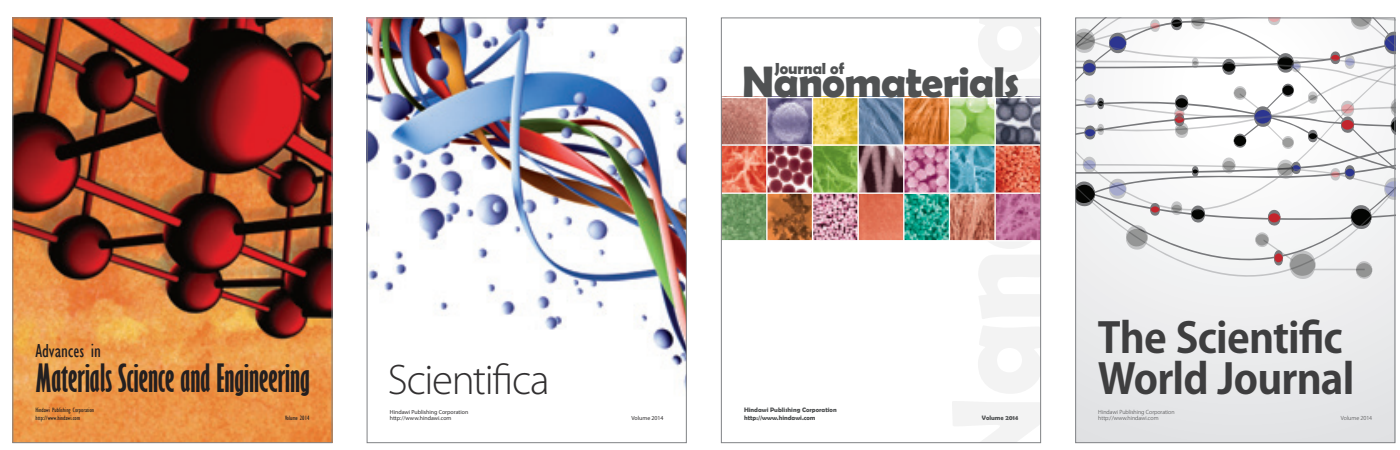

\section{The Scientific World Journal}
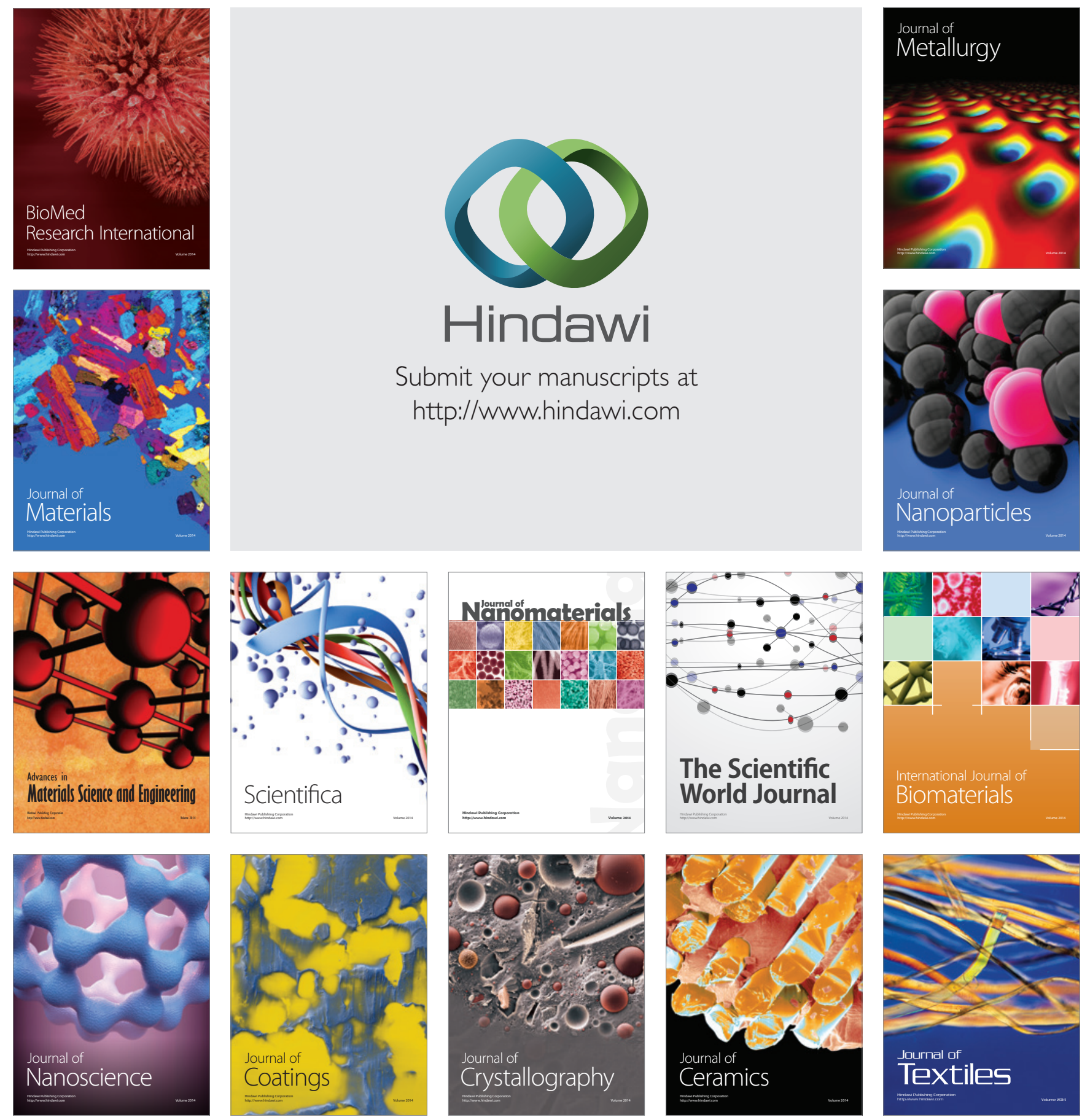